\title{
Molecular diagnosis of Theileria and Babesia species infecting cattle in Northern Spain using reverse line blot macroarrays Josune García-Sanmartín ${ }^{1}$, Daniel Nagore², Ana L García-Pérez¹, Ramón A Juste ${ }^{1}$ and Ana Hurtado*1
}

Address: ${ }^{1}$ Department of Animal Health, NEIKER - Instituto Vasco de Investigación y Desarrollo Agrario, Berreaga 1, 48160 Derio, Bizkaia, Spain and 2Proteomika, S.L., Parque Tecnologico de Zamudio, Edif. 801, 48160 Derio, Bizkaia, Spain

Email: Josune García-Sanmartín - jgarcia@neiker.net; Daniel Nagore - dnagore@proteomika.com; Ana L García-Pérez - agarcia@neiker.net; Ramón A Juste - rjuste@neiker.net; Ana Hurtado* - ahurtado@neiker.net

* Corresponding author

Published: 09 May 2006

BMC Veterinary Research 2006, 2:16 doi:10.1186/1746-6/48-2-16

This article is available from: http://www.biomedcentral.com/l746-6/48/2/16

(c) 2006 García-Sanmartín et al; licensee BioMed Central Ltd.

This is an Open Access article distributed under the terms of the Creative Commons Attribution License (http://creativecommons.org/licenses/by/2.0), which permits unrestricted use, distribution, and reproduction in any medium, provided the original work is properly cited.
Received: 13 March 2006
Accepted: 09 May 2006

\begin{abstract}
Background: Piroplasmosis in cattle is caused by tick-borne haemoprotozoan parasites of the genera Theileria and Babesia. Molecular detection techniques offer higher sensitivity and specificity than microscopy examination methods and serological tests. A reverse line blot (RLB) macroarray that included generic and species-specific probes for Theileria annulata, Theileria buffeli, Babesia bovis, Babesia bigemina, Babesia divergens and Babesia major was used to study the presence and identity of the piroplasm species infecting 263 bovine blood samples from 79 farms, most of them in Northern Spain. Microscopy examination of blood smears and haematology were also performed whenever possible to identify animals with parasitaemia.
\end{abstract}

Results: RLB hybridisation identified infection in $54.0 \%$ of the samples, whereas only $28.8 \%$ were positive by microscopy examination. The most frequently found species was $T$. buffeli, present in $42.6 \%$ of the samples. T. annulata was found in 22 samples (8.4\%) from 12 farms, including 9 farms ( 4 samples) located in Northern Spain where presence of the vector is not very common. Babesia infections were less frequently detected: B. major was found in $3.0 \%$ of the samples, B. bigemina in $2.7 \%$, B. bovis in $2.3 \%$ and $B$. divergens in $1.1 \%$. Mixed infections were detected in 14 samples, accounting for six different combinations of species.

Conclusion: This is the first report in which B. major and B. divergens have been detected in Spain using molecular identification techniques and the first time that $B$. bovis has been detected in Northern Spain. The detection of T. annulata in Northern Spain suggests that the distribution of Mediterranean theileriosis might be changing. Samples with positive RLB hybridisation but negative microscopy had haematology values within the normal ranges suggesting that they corresponded to chronic carriers that may serve as reservoirs of the infection. In this sense, sensitive and specific laboratorial tests like RLB that clearly identify the parasite and can detect subclinical infections are essential to establish good control measures. 


\section{Background}

Piroplasmosis in cattle is caused by tick-borne haemoprotozoan parasites comprising several Theileria and Babesia species $[1,2]$. These diseases are of serious health and economic concern in several parts of the world, including tropical and temperate countries. In Spain the main malignant piroplasm species causing severe theileriosis signs is Theileria annulata, with infections described in Southern and Mediterranean areas [3-6], where the tick vector (Hyalomma sp.) is present $[7,8]$. However, the most widespread theileria is Theileria buffeli, which is in general considered a benign species. Regarding Babesia spp., several pathogenic species have been reported in Central and Southern Spain (B. major, B. bovis, B. divergens and $B$. bigemina) [7], though only $B$. bigemina and $B$. bovis have been detected in these areas in recent epidemiological studies using molecular methods [3,9]. Different weather conditions in different parts of Spain determine tick vector distribution, and therefore, the incidence of piroplasmosis. Unlike the dry and hot Mediterranean climate of eastern and southern parts, Northern Spain covers two different climatic zones: an Atlantic climate in the northern coast with frequent rainfall and mild temperatures, and a Continental Mediterranean climate in the interior central plateau with colder winters and warmer summers. Hence, the main tick species infesting cattle in Northern Spain are Ixodes ricinus, Haemaphysalis punctata, Dermacentor spp. and Rhipicephalus bursa $[10,11]$. Moving in a southerly direction, ticks of the genus Hyalomma become more prevalent, and similarly, other tick species such as $I$. ricinus and Dermacentor reticulatus become nearly absent $[7,8]$. Therefore, a different situation regarding bovine piroplasms diversity would be expected in this northern area compared to other parts of Spain. However, there are no studies on bovine piroplasmosis in Northern Spain using molecular identification techniques.

Laboratorial diagnosis of clinical infection by piroplasms in cattle is usually based on the detection of the parasite in Giemsa-stained blood smears. Carrier animals, in which low numbers of erythrocytes remain infected, are important contributors to the transmission of the infection by tick bites. Hence, detection of piroplasms in carrier animals is very important to control the infection. However, detection of piroplasms by microscopy is not easy and it is generally not possible to discriminate pathogenic from non-pathogenic species that may occur simultaneously within the same host. Although serological tests can be used to detect circulating antibodies, crossreactivity with antibodies directed against other species of piroplasms has been reported [12]. Moreover, antibodies tend to disappear in long-term carriers, whereas piroplasms persist. Therefore, animals with a negative serological test can still be the source of the infection and infect ticks. Several PCR-based diagnosis procedures for the identification of these parasites have been developed [13-16]. However, increased sensitivity and specificity can be achieved by combining PCR with a specific hybridisation by means of reverse line blot (RLB), a macroarray that is also capable of identifying mixed infections [9,17-20].

The aim of this study was to investigate the presence and identity of piroplasm species infecting the bovine blood samples with suspicion of piroplasmosis submitted to the Diagnostic Service of our Institute from Northern Spain in recent years using reverse line blot (RLB) macroarrays.

\section{Results}

Microscopy examination of blood samples identified intracellular forms morphologically compatible with piroplasms in $28.8 \%$ of them (Table 1), $82.5 \%$ corresponding to Theileria spp. and $17.5 \%$ to Babesia spp. Piroplasms were detected by microscopy in $37.8 \%$ of the animals with clinical signs compatible with piroplasmosis and in $24.6 \%$ of those with unspecific signs. In samples with Babesia infection red cell parameters (erythrocyte count $4.18 \pm 1.19 \times 10^{6} \mathrm{~mm}^{-3}$, PCV $0.19 \pm 0.039 \mathrm{l} / \mathrm{l}$, and haemoglobin $5.9 \pm 1.54 \mathrm{~g} / \mathrm{dl}$ ) were significantly lower $(\mathrm{P}$ $<0.05$ ) than in those with Theileria spp. (erythrocyte count $5.58 \pm 0.50 \times 10^{6} \mathrm{~mm}^{-3}$, PCV $0.27 \pm 0.023 \mathrm{l} / \mathrm{l}$, and haemoglobin $9.7 \pm 0.79 \mathrm{~g} / \mathrm{dl}$ ) or negative (erythrocyte count $5.85 \pm 1.41 \times 10^{6} \mathrm{~mm}^{-3}$, PCV $0.30 \pm 0.096 \mathrm{l} / \mathrm{l}$, and haemoglobin $10.4 \pm 1.78 \mathrm{~g} / \mathrm{dl})$. Red cell parameters in samples with Theileria spp. were lower than in negative samples but differences were not significant. Samples with mixed infections (Babesia spp. and Theileria spp.) presented intermediate values (erythrocyte count 5.01 \pm 1.53 $\times 10^{6} \mathrm{~mm}^{-3}$, PCV $0.25 \pm 0.065 \mathrm{l} / \mathrm{l}$, and haemoglobin $8.4 \pm$ $2.11 \mathrm{~g} / \mathrm{dl}$ ) that were significantly lower than in negative samples in terms of PCV. Leukocyte countings were also significantly lower $\left(4.46 \pm 0.96 \times 10^{3} \mathrm{~mm}^{-3}\right)$ in animals with Babesia than in negative $\left(7.18 \pm 0.56 \times 10^{3} \mathrm{~mm}^{-3}\right)$ or Theileria-infected animals $\left(7.38 \pm 0.77 \times 10^{3} \mathrm{~mm}^{-3}\right)(\mathrm{P}<$ 0.05).

142 of the blood samples analysed hybridised with at least one of the species-specific probes of the RLB array, finding positive signals with all six probes (Fig. 1). Thus, positive samples increased to $54.0 \%$ when analysed by RLB (Table 1), with piroplasms being detected in $60.9 \%$ of the animals with suspicion of piroplasmosis and in $50.0 \%$ of those with unspecific signs. T. buffeli was the most frequently found species being present in $42.6 \%$ of the samples (112/263), mainly as a single infection $(90.2 \%, 101 / 112)$ but also in mixed infections $(9.8 \%, 11 /$ $112)$. The highly pathogenic species $T$. annulata was second in detection with $8.4 \%$ of the samples positive (22/ $263)$, in 15 of them as a single infection (68.2\%) and as part of mixed infections in the remaining 7 samples $(31.8 \%)$. T. annulata was found in 12 farms distributed 
Table I: Distribution and frequency (\%) of piroplasm species.

\begin{tabular}{|c|c|c|c|c|}
\hline \multirow[b]{2}{*}{ Piroplasm species } & \multicolumn{2}{|c|}{ RLB } & \multicolumn{2}{|c|}{ Microscopy } \\
\hline & $\mathbf{N}$ & $\%$ & $\mathbf{N}$ pos (anal) ${ }^{a}$ & $\%$ \\
\hline T. buffeli & 101 & 38.4 & & \\
\hline T. annulata & 15 & 5.7 & & \\
\hline Total single infections with Theileria spp. & 116 & 44.1 & $50(I I I)$ & 19.8 \\
\hline 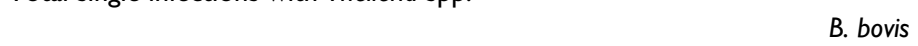 & 6 & 2.2 & & \\
\hline B. bigemina & 0 & 0.0 & & \\
\hline B. divergens & 1 & 0.4 & & \\
\hline B. major & 5 & 1.9 & & \\
\hline TOTAL single infections with Babesia spp. & 12 & 4.5 & $3(I I)$ & 1.2 \\
\hline T. annulata $+T$. buffeli & 2 & 0.8 & & \\
\hline T. annulata $+T$. buffeli + B. bigemina & 2 & 0.8 & & \\
\hline T. annulata + B. bigemina & 3 & 1.1 & & \\
\hline T. buffeli + B. bigemina & 2 & 0.8 & & \\
\hline T. buffeli $+B$. divergens & 2 & 0.8 & & \\
\hline T. buffeli + B. major & 3 & 1.1 & & \\
\hline TOTAL mixed infections & 14 & 5.4 & $10(13)$ & 3.9 \\
\hline NEGATIVE & 121 & 46.0 & $10(1 / 8)$ & 3.9 \\
\hline TOTAL analysed & 263 & & 253 & \\
\hline
\end{tabular}

a, number of samples positive by microscopy examination (Theileria spp. or Babesia spp.) of the total number of samples analysed within each group of RLB-identified species.

throughout Spain, including the 3 farms from the endemic regions ( 2 from Southern Spain and 1 from the Mediterranean area) that accounted for 8 animals with single infection. The remaining 9 farms positive to $T$. annulata were in Northern Spain and they appeared both as single and mixed infections. In six of these farms only 1 or 2 animals were analysed, being all of them positive to T. annulata (as a mixed infection in half of them). In the other three farms the number of animals sampled varied among 4 ( 1 animal positive to $T$. annulata), 5 (2 positive) and 13 (3 positive), and other piroplasm species besides T. annulata were also found in all three farms.

Presence of Babesia species was less frequently detected, with 24 samples positive (9.1\%) either as single or mixed infection (Table 1). The species most frequently found was B. major, present in 8 animals (3.0\%) from 3 farms. In five samples it was found as a single infection whereas in the remaining 3 it appeared combined with T. buffeli. B. bigemina was detected in 7 animals (2.7\%) from 5 farms

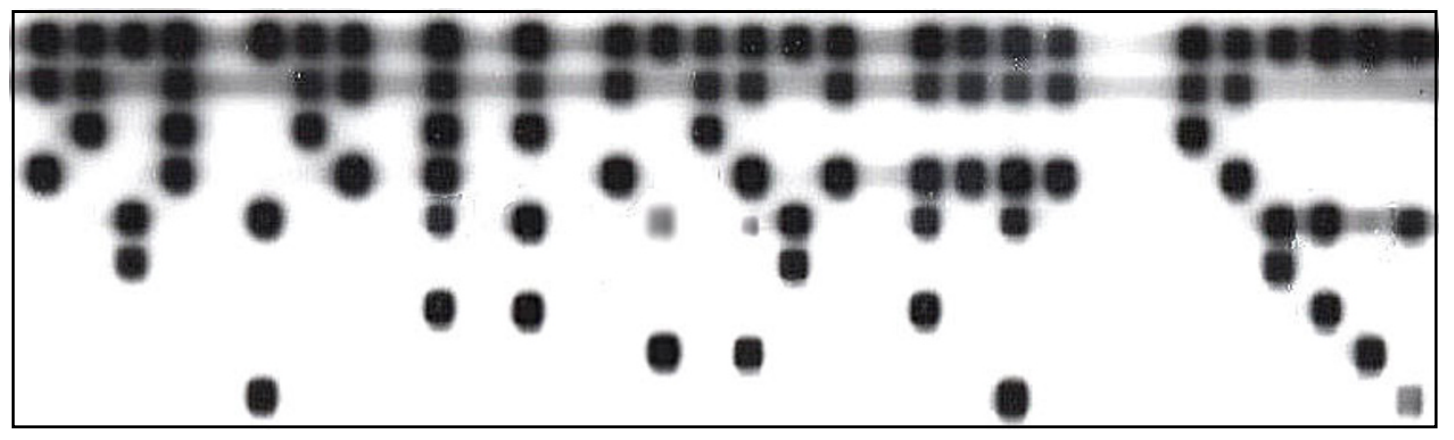

catchall

Theileria spp.

T. annulata

T. buffeli

Babesia spp.

$B$. bovis

B. bigemina

$B$. divergens

B. major

$\begin{array}{llllllllllllllllllllllllllllllll}1 & 2 & 3 & 4 & 5 & 6 & 7 & 8 & 9 & 10 & 11 & 12 & 13 & 14 & 15 & 16 & 17 & 18 & 19 & 20 & 21 & 22 & 23 & 24 & 25 & 26 & 27 & 28 & 29 & 30 & 31 & 32\end{array}$

\section{Figure I}

Reverse line blot macroarray of the bovine blood samples and control clones. Oligonucleotide probes are indicated in rows, and samples are applied in columns as follows: lanes I-24, field samples; lane 25, genomic DNA of uninfected cow; lane 26, negative control; lane 27, T. annulata I8S rRNA gene clone; lane 28, T. buffeli I8S rRNA gene clone; lane 29, B. bovis I8S rRNA gene clone; lane 30, B. bigemina I8S rRNA gene clone; lane 3I, B. divergens I8S rRNA gene clone; lane 32, B. major I8S rRNA gene clone. 
and it always appeared as part of a mixed infection with one or both species of Theileria. Conversely, B. bovis was only found as a single infection present in 6 animals $(2.2 \%)$ from 3 farms from Northern Spain. Finally, $B$. divergens was only found in 3 samples (1.1\%) from 3 farms, in one animal it occurred as a single infection while in the other two, $B$. divergens was detected along with $T$. buffeli.

There was no significant difference in the percentage of animals infected with T. annulata or T. buffelli between the group of animals with clinical suspicion of piroplasmosis and those with unspecific signs. However, detection of $B$. major and $B$. bovis was significantly associated to the group of animals with clinical suspicion of piroplasmosis $(\mathrm{P}<$ 0.05).

Mixed infections were detected in a total of 14 samples, accounting for six different combinations of species (Table 1). One of them included three species and the remaining five were composed of a combination of two species. Whereas $T$. buffeli and T. annulata were found together in 4 samples ( 2 in combination with $B$. bigemina), no mixed infections with two Babesia species were detected. T. buffeli, the most prevalent species, was found in combination with all the other species except with $B$. bovis, which was only found in single infections.

When compared with microscopy, RLB detected a positive signal in $40.0 \%$ of the samples with negative microscopy (72 samples), identifying T. buffeli in $75.0 \%$ of them,T. annulata in 15.3\%, and several species of Babesia in $13.9 \%$. However, 10 samples positive by microscopy were not detected by RLB analysis. When looking only to the RLB results of the animals with negative microscopy (subclinical infections), the lowest red cell parameters were found in one animal infected with $B$. major $(\mathrm{n}=1$, erythrocyte count $3.02 \times 10^{6} \mathrm{~mm}^{-3}$, PCV $0.17 \mathrm{l} / \mathrm{l}$, and haemoglobin $5.23 \mathrm{~g} / \mathrm{dl}$ ) and the animals infected with $B$. bovis ( $=6$, erythrocyte count $5.12 \pm 1.04 \times 10^{6} \mathrm{~mm}^{-3}$, PCV 0.24 $\pm 0.042 \mathrm{l} / \mathrm{l}$, and haemoglobin $7.02 \pm 1.95 \mathrm{~g} / \mathrm{dl}$ ), whereas animals infected with species of Theileria had lower values than negative animals but within the normal ranges.

Although the number of samples submitted from each farm was in general quite small (more than one sample was only submitted from $52 \%$ of the farms), 2 pathogenic species (i.e. different to T. buffeli) were found in 5 farms, located all of them in Northern Spain. T. annulata was present in all five, along with B. bigemina in four of them and with $B$. bovis in the fifth.

\section{Discussion}

The technique used in this study allowed the simultaneous detection and identification of different bovine Theileria and Babesia species using oligonucleotide probes whose specificity has been previously determined $[9,17,19]$. Moreover, the combination of a generic Babesia and Theileria PCR targeting the V4 region of the 18S rRNA gene and a hybridisation with specific probes provided high sensitivity $[9,19]$. Since detection of the parasite in Giemsa-stained blood smears is the technique that has been traditionally used for diagnosis of piroplasmosis, whenever possible RLB and microscopy examination were performed in parallel. Besides, positive microscopy allowed us to identify animals with parasitaemia. Thus, RLB hybridisation detected piroplasms in 72 samples that were negative by microscopy examination reaching a total of $54.0 \%$ of positive samples, while only $28.8 \%$ could be detected by microscopy. In any case, and even though RLB was significantly more sensitive than microscopy, piroplasms were detected by microscopy in 10 samples negative by RLB. This discrepancy could be due to subjective interpretation of microscopy examination or bad conditions of the samples (e.g. haemolysis or presence of clots). Whatever the reason, the inclusion of the catchall and genus-specific probes guarantees that this discrepancy cannot be ascribed to infection with new piroplasm species.

T. buffeli was the most prevalent species with $42.6 \%$ of the samples positive by RLB. This value is much lower than

Table 2: Sequence of oligonucleotide probes covalently linked to the membrane.

\begin{tabular}{|c|c|c|c|}
\hline Probe & Sequence $\left(5^{\prime}-3^{\prime}\right)$ & $\operatorname{Tm}\left({ }^{\circ} \mathrm{C}\right)$ & Reference \\
\hline catchall & TAATGGTTAATAGGA(A/G)C(A/G)GTTG & $54.7^{\mathrm{a}}$ & {$[17]$} \\
\hline Theileria spp. & GTTGAATTTCTGCT(A/G)CAT(C/T)GC & $55.9 \mathrm{a}$ & {$[19]$} \\
\hline Babesia spp. & СCT(G/T)GGTAATGGTTAATAGGAA & $55.6^{\mathrm{a}}$ & [20] \\
\hline T. annulata & ССTCTGGGGTCTGTGCA & 57.6 & {$[17]$} \\
\hline T. buffeli & GGCTTATTTCGG(A/T)TTGATTTT & $52.0^{\mathrm{a}}$ & [9] \\
\hline B. bigemina & CGTTTTTTCCCTTTTGTTGG & 53.2 & [9] \\
\hline B. bovis & CAGGTTTCGCCTGTATAATTGAG & 58.9 & [9] \\
\hline B. divergens & GTTAATATTGACTAATGTCGAG & 52.8 & [9] \\
\hline B. major & TCCGACTTTGGTTGGTGT & 53.7 & [17] \\
\hline
\end{tabular}

a $\mathrm{Tm}$ for degenerate oligonucleotides are approximate values 
that reported in Eastern Spain using the same technology [3], but higher than in Northeastern Portugal [21]. T. buffeli was mainly found as a single infection, but it was also the most common species found in mixed infections. Although Stockham and cols. [22] described a case of clinical disease associated to T. buffeli infection, this species is generally considered as non-pathogenic. The results obtained in this study would confirm this idea, since samples with organisms morphologically compatible with Theileria spp. by microscopy examination and identified as T. buffeli by RLB presented red cell parameters within the normal ranges. However, this does not exclude the possibility that subclinical infections with $T$. buffeli might cause a production decrease. Further research is therefore needed to establish the significance and effect on bovine production of this highly prevalent species. Conversely, $T$. annulata is clearly recognised as a very pathogenic theileria that has been mainly described in temperate areas as the causative agent of Mediterranean theileriosis. In Spain most of the cases are generally restricted to southern and eastern parts of the country, where the tick vector (Hyalomma spp.) is endemic $[4,7,8]$. In this study T. annulata was found in 22 samples from 12 farms, 3 in the endemic regions and 9 in Northern Spain. The lower incidence of $T$. annulata compared to T. buffeli ( $8.4 \%$ vs. $42.6 \%)$ is in agreement with the different geographic distribution of the tick vectors associated to each species. Thus, whereas the vector of T. buffeli (Haemaphysalis spp.) is quite common in Northern Spain $[23,24]$, ticks of the genus Hyalomma seem to be endemic of southern and eastern parts of the country and reports on its presence in Northern Spain are only sporadic $[7,8,25]$. In this sense, recent data ( $\mathrm{S}$. Jiménez, personal communication) have revealed the recent emergence of Hyalomma ticks in cattle in La Rioja (a province in Northern Spain), suggesting that the distribution of Mediterranean theileriosis might be changing, probably due to changes in climatic conditions and vegetation that affect vector distribution.

Infection with Babesia species accounted for $9.1 \%$ of the samples corresponding to $3.0 \%$ of $B$. major, $2.7 \%$ of $B$. bigemina, $2.2 \%$ of $B$. bovis and $1.1 \%$ of $B$. divergens. However, this is the first time that $B$. major and $B$. divergens are detected in Spain using molecular techniques. In previous reports species identification had been based on morphological examinations by microscopy. Tick vectors associated to these species seem to be H. punctata and I. ricinus, respectively [26], which are very abundant in Northern Spain $[23,24]$. B. bovis is regarded as the most pathogenic bovine Babesia species and so far in Spain it had only been reported in Balearic Islands (Eastern Spain) [27], although it had been identified before in Southern and Western Spain by microscopy examination [7]. B. bovis is transmitted by ticks of three genera (Ixodes, Rhipicephalus and Boophilus) [26], although only the first two are found in
Northern Spain. In our study we found 6 positive samples from 3 farms in Northern Spain with a history of piroplasmosis. In two farms B. bovis was detected in 3 of 4 samples, and 2 out of 6 , respectively. In the third farm, samples had been submitted to the laboratory at four different time points (four samples) throughout 3 years with reports of unspecific clinical signs. In addition to B. bovis, T. annulata and T. buffeli were also detected in one animal each, suggesting that different piroplasms were circulating within that farm. However, in none of the 6 positive samples was $B$. bovis found in a mixed infection.

Again, as in the case of single infections, T. buffeli was also the most prevalent species in mixed infections. It appeared in 11 of them $(78.6 \%)$, in combinations of two or even three, with all the other species except B. bovis. This was the only species never found in combination with other piroplasms in our study, although Almeria et al. [3] found it in a mixed infection with Theileria sp. Opposite to B. bovis, B. bigemina was only detected as a mixed infection with either T. buffeli or T. annulata or both. This same situation was also found by Almeria et al. [3]. Although the number of samples with mixed infections is relatively small, the association of certain piroplasm species and not others in mixed infections might be linked to the tick vectors present in the vegetation of a certain area.

The 72 samples with positive RLB hybridisation but negative microscopy, corresponded in most of the cases to infections with Theileria species $(75.0 \%$ of $T$. buffeli and $15.3 \%$ of T. annulata) and to lesser extent with Babesia species $(13.9 \%)$. These samples (except for B. major and $B$. bovis) had haematology values within the normal ranges suggesting that they would correspond to animals that have overcome the parasitaemia but remain as carriers of the haemoparasite. These chronic asymptomatic carriers may serve as reservoirs of the infection and therefore be of serious concern in terms of piroplasmosis control. The lower prevalence of Babesia species detected among carrier cattle as compared to carriers of Theileria spp., also observed in sheep and horses $[18,19]$, would be explained by the fluctuations in parasitaemia that occur during the chronic phase of infection by Babesia species $[9,28,29]$ or the low numbers of intraerythrocytic piroplasms in the circulating bloodstream of Babesia carriers [30].

\section{Conclusion}

This study revealed that subclinical infections are common and that bovine piroplasmosis does not have a clear pattern that allows clinicians to undoubtedly identify animals with babesiosis or theileriosis, particularly in the latter case, in which clinical signs can be highly unspecific. Therefore, sensitive and specific laboratorial tests like RLB, which clearly identify the parasite and can detect asymp- 
tomatic carriers, are essential to establish good control measures and to avoid unnecessary treatments. In the light of the advantages of RLB, a universal macroarray could be designed to identify all possible piroplasms infecting livestock. The present work is the continuation of our previous studies dealing with the genetic diversity, epidemiology and phylogenetic analysis of piroplasms infecting horses and sheep $[18,19]$. The application of macroarrays to piroplasm discrimination would help to investigate the host susceptibility and parasite-host specificity relationships.

\section{Methods}

\section{Clinical samples}

A total of 263 bovine blood samples submitted between the years 2000 and 2004 to the Diagnostic Service of NEIKER were included in this study: 88 with clinical suspicion of piroplasmosis (hyperthermia, anaemia, and/or haemoglobinuria, icterus, associated to tick infection) and 175 from animals with unspecific signs (anorexia, body weight loss, reduced milk production, abortion and reproductive failure) for which haemoparasites analysis was requested. Samples were collected from 77 farms from the northern half of Spain and two from Southern Spain. The number of samples submitted from each farm varied from 1 to 30 with the following distribution: 1 sample from 38 farms, 2-10 samples from 36 farms and 11-30 samples in 5 farms. Blood samples submitted in EDTA containing tubes were analysed by haematological and parasitological examination, and stored at $-20^{\circ} \mathrm{C}$ until subsequent DNA purification and hybridisation analysis.

\section{Haematological and microscopy examination}

Leukocyte and erythrocyte counting was carried out with an electronic counter (Iber-cell, Barcelona, Spain). Packed cell volume (PCV) was measured by the standard microhaematocrit method, and haemoglobin concentration was determined by a colorimetric assay in a spectrophotometer. Leukocyte differential counting was carried out by thin blood smears stained with Giemsa and analysed under an oil-immersion objective, differentiating at least 100 cells. Giemsa-stained slides were searched for intracellular forms with morphology compatible with Theileria or Babesia under an oil-immersion objective $(100 \times)$.

\section{DNA extraction}

DNA was extracted using the QIAamp DNA Mini kit (Qiagen, Hilden, Germany) for DNA purification from whole blood and DNA yields were determined with a NanoDrop ${ }^{\circledR}$ ND-1000 Spectrophotometer (NanoDrop Technologies, DE, USA).

\section{PCR amplification and RLB hybridisation}

Prior to reverse line blot (RLB) hybridisation the hypervariable V4 region of the $18 \mathrm{~S}$ rRNA gene of the genera Theileria and Babesia was amplified using primers RLB-F (5'-GACACAGGGAGGTAGTGACAAG-3') and RLB-R (biotin-5'-CTAAGAATTTCACCTCTGACAGT-3') (MWG Biotech AG, Germany), as adapted by Georges et al. [17]. Reactions were performed in $25 \mu \mathrm{l}$ volumes as previously described $[18,19]$. Oligonucleotide probes containing a $N$-(trifluoroacetamidohexyl-cyanoethyl, $N, N$-diisopropyl phosphoramidite [TFA])- $\mathrm{C}_{6}$ amino linker were synthesised by MWG Biotech AG (Germany). Sequences of the oligonucleotide probes used are summarised in Table 2. The oligonucleotides were diluted in $160 \mu \mathrm{l}$ of $500 \mathrm{mM}$ $\mathrm{NaHCO}_{3}(\mathrm{pH} 8.4)$ to a final concentration of $8 \mu \mathrm{M}$. Preparation of RLB membrane and hybridisation were carried out as previously described $[18,19]$. After developing, the PCR products were stripped from the membrane $[18,19]$ and membranes reprobed a maximum of 8 times.

Plasmids including the amplicon of the V4 region of the $18 \mathrm{~S}$ rRNA gene of each of the six species analysed were constructed as previously described $[18,19]$ and used as positive controls. To monitor for false-positive results, negative controls included during DNA extraction and PCR amplification were subjected to RLB hybridisation.

\section{Statistical analysis}

Haematimetric variables, microscopic and RLB data were submitted to analysis of variance and comparison of means using the GLM procedure on the SAS statistical package (Version 8.0). Comparison of frequencies for testing associations between piroplasm types and clinical disease were carried out with Chi square or Fisher exact tests. $P$ values less than 0.05 were considered significant, and quantitative results are presented as mean \pm standard error.

\section{Competing interests}

The author(s) declare that they have no competing interests.

\section{Authors' contributions}

JG carried out the experimental work and participated in drafting of the manuscript. DN carried out part of the experimental work and critically revised the manuscript. ALG interpreted data and participated in writing the manuscript. RAJ performed the statistical analysis and participated in the critical reading of the publication. $\mathrm{AH}$ participated in the design and coordination of the study and drafted the manuscript. All authors read and approved the final manuscript.

\section{Acknowledgements}

We thank Dr. P. García Fernández (CIFA, Granada) for kindly providing DNA of T. annulata and I. Povedano for helping with blood samples 
processing. This work was conducted under financial support from the Instituto Nacional de Investigación y Tecnología Agraria y Alimentaria (INIA) (RTA02-00I), and the Department of Agriculture and Fisheries of the Basque Country Government. J.G. is the recipient of a predoctoral fellowship from INIA.

\section{References}

I. Preston PM: Theilerioses. In Encyclopedia of arthropod-transmitted infections of man and domesticated animals Edited by: Wallingford MW. UK: CABI Publishing; 2001:487-502.

2. Uilenberg G: Babesiosis. In Encyclopedia of arthropod-transmitted infections of man and domesticated animals Edited by: Wallingford MW. UK: CABI Publishing; 2001:53-60.

3. Almeria S, Castella J, Ferrer D, Gutierrez JF, Estrada-Pena A, Sparagano O: Reverse line blot hybridization used to identify hemoprotozoa in Minorcan cattle. Ann N Y Acad Sci 2002, 969:78-82.

4. Habela M, Rol JA, Anton JM, Pena J, Corchero E, van HI, Jongejan E: Epidemiology of Mediterranean theileriosis in Extremadura region, Spain. Parassitologia I999, 4 I (Suppl I):47-5I.

5. Martin-Sanchez J, Viseras J, Adroher FJ, Garcia-Fernandez P: Nested polymerase chain reaction for detection of Theileria annulata and comparison with conventional diagnostic techniques: its use in epidemiology studies. Parasitol Res 1999, 85:243-245.

6. Viseras J, Hueli LE, Adroher FJ, Garcia-Fernandez P: Studies on the transmission of Theileria annulata to cattle by the tick Hyalomma lusitanicum. Zentralbl Veterinarmed B I999, 46:505-509.

7. Cordero del Campillo M, Castañón Ordoñez L, Reguera Feo A: ÍndiceCatálogo de Zooparásitos Ibéricos León, Spain: Secretariado de Publicaciones Universidad de León; 1994.

8. Estrada-Peña A, Boauttorur JL, Camicas J-L, Walker AR: Ticks of domestic animals in the Mediterranean region. A guide to identification of species Zaragoza, Spain: University of Zaragoza; 2004.

9. Gubbels JM, de Vos AP, van der Weide M, Viseras J, Schouls LM, de Vries E, Jongejan F: Simultaneous detection of bovine Theileria and Babesia species by reverse line blot hybridization. J Clin Microbiol 1999, 37:I782-1789.

10. Moreno JA, Estrada-Pena A: Prevalence and seasonalactivity of Ixodes ricinus (Acari: Ixodidae) on domestic ruminants of the Basque country, Spain. Exp Appl Acarol 1997, 2 I:4 I-48.

II. Moreno JA, Barral M, Garcia-Perez AL, Fernandez de Luco D, Estrada $A$, Juste RA: Seasonal dynamics of tick populations on sheep and cattle in the Basque Country, Spain. Association of Veterinary Teachers and Research Workers: Scarborough :34. 6-8 April 1993

12. Papadopoulos B, Brossard M, Perie NM: Piroplasms of domestic animals in the Macedonia region of Greece. 2. Piroplasms of cattle. Vet Parasitol 1996, 63:57-66.

13. Birkenheuer AJ, Levy MG, Breitschwerdt EB: Development and evaluation of a seminested PCR for detection and differentiation of Babesia gibsoni (Asian genotype) and B. canis DNA in canine blood samples. J Clin Microbiol 2003, 41:4172-4I77.

14. Criado-Fornelio A, Martinez-Marcos A, Buling-Sarana A, Barba-Carretero JC: Molecular studies on Babesia, Theileria and Hepatozoon in southern Europe. Part II. Phylogenetic analysis and evolutionary history. Vet Parasitol 2003, I I 4: I 73-194.

15. Rampersad J, Cesar E, Campbell MD, Samlal M, Ammons D: A field evaluation of PCR for the routine detection of Babesia equi in horses. Vet Parasitol 2003, I | 4:81-87.

16. Figueroa JV, Chieves LP, Johnson GS, Buening GM: Multiplex polymerase chain reaction based assay for the detection of Babesia bigemina, Babesia bovis and Anaplasma marginale DNA in bovine blood. Vet Parasitol 1993, 50:69-8I.

17. Georges K, Loria GR, Riili S, Greco A, Caracappa S, Jongejan F, Sparagano $O$ : Detection of haemoparasites in cattle by reverse line blot hybridisation with a note on the distribution of ticks in Sicily. Vet Parasitol 200I, 99:273-286.

18. Nagore D, Garcia-Sanmartin J, Garcia-Perez AL, Juste RA, Hurtado A: Identification, genetic diversity and prevalence of Theileria and Babesia species in a sheep population from Northern Spain. Int J Parasitol 2004, 34: I059-1067.

19. Nagore D, Garcia-Sanmartin J, Garcia-Perez AL, Juste RA, Hurtado A: Detection and identification of equine Theileria and Babesia species by reverse line blotting: epidemiological survey and phylogenetic analysis. Vet Parasitol 2004, I 23:4I-54.

20. Schnittger L, Yin H, Qi B, Gubbels JM, Beyer D, Niemann S, Jongejan $E$, Ahmed JS: Simultaneous detection and differentiation of
Theileria and Babesia parasites infecting small ruminants by reverse line blotting. Parasitol Res 2004, 92:189-196.

21. Brigido C, Pereira da Fonseca I, Parreira R, Fazendeiro I, do Rosario VE, Centeno-Lima S: Molecular and phylogenetic characterization of Theileria spp. parasites in autochthonous bovines (Mirandesa breed) in Portugal. Vet Parasitol 2004, I 23: 17-23.

22. Stockham SL, Kjemtrup AM, Conrad PA, Schmidt DA, Scott MA, Robinson TW, Tyler JW, Johnson GC, Carson CA, Cuddihee P: Theileriosis in a Missouri beef herd caused by Theileria buffeli: case report, herd investigation, ultrastructure, phylogenetic analysis, and experimental transmission. Vet Pathol 2000, 37:II-2I.

23. Barandika JF, Berriatua E, Barral M, Juste RA, Anda P, Garcia-Perez $A L$ : Risk factors associated with ixodid tick species distributions in the Basque region in Spain. Med Vet Entomol 2006 [http:/ /www.blackwell-synergy.com/doi/abs/10.11111/j.13652915.2006.00619.x].

24. Barral M, Garcia-Perez AL, Juste RA, Fernandez de Luco D, Dehesa V: Distribución y actividad de los ixódidos presentes en la vegetación de la Comunidad Autónoma Vasca Vitoria, Spain: Servicio Central de Publicaciones del Gobierno Vasco; 1993.

25. Encinas-Grandes A: Ticks of the province of Salamanca (Central/NW Spain). Prevalence and parasitization intensity in dogs and domestic ungulates. Ann Parasitol Hum Comp 1986, 61:95-107.

26. Soulsby EJL: Helminths, arthropods and protozoa of domesticated animals Philadelphia: Lea and Febiger; 1982.

27. Almeria S, Castella J, Ferrer D, Sparagano, Estrada-Pena A: First report of Babesia bovis in Spain. Vet Rec 200I, I49:716-7I7.

28. Calder JA, Reddy GR, Chieves L, Courtney CH, Littell R, Livengood JR, Norval RA, Smith C, Dame JB: Monitoring Babesia bovis infections in cattle by using PCR-based tests. J Clin Microbiol 1996, 34:2748-2755.

29. Figueroa JV, Chieves LP, Johnson GS, Buening GM: Detection of Babesia bigemina -infected carriers by polymerase chain reaction amplification. J Clin Microbiol 1992, 30:2576-2582.

30. Homer MJ, Aguilar-Delfin I, Telford SR, Krause PJ, Persing DH: Babesiosis. Clin Microbiol Rev 2000, I3:45 I-469.

Publish with BioMed Central and every
scientist can read your work free of charge
"BioMed Central will be the most significant development for
disseminating the results of biomedical research in our lifetime."
Sir Paul Nurse, Cancer Research UK
Your research papers will be:
• available free of charge to the entire biomedical community
• peer reviewed and published immediately upon acceptance
• cited in PubMed and archived on PubMed Central
• yours - you keep the copyright
Submit your manuscript here:
http://www.biomedcentral.com/info/publishing_adv.asp

